\title{
Knowledge, Attitude and Practices of Food Hygiene among Food Vendors in Owerri, Imo State, Nigeria
}

\author{
Anthony C. Iwu ${ }^{1}$, Kenechi A. Uwakwe ${ }^{2}$, Chukwuma B. Duru ${ }^{2}$, Kevin C. Diwe ${ }^{2}$, \\ Henry N. Chineke, Irene A. Merenu², Uche R. Oluoha1, Ugochukwu C. Madubueze", \\ Emmanuel Ndukwu1, Ikechi Ohale ${ }^{1}$ \\ ${ }^{1}$ Department of Community Medicine, Imo State University Teaching Hospital, Orlu, Nigeria \\ ${ }^{2}$ Department of Community Medicine, Imo State University, Owerri, Nigeria \\ ${ }^{3}$ Department of Family Medicine, Imo State University Teaching Hospital, Orlu, Nigeria \\ ${ }^{4}$ Department of Community Medicine, Federal Teaching Hospital, Abakaliki, Nigeria \\ Email: *iwuchinedu@yahoo.com
}

How to cite this paper: Iwu, A.C., Uwakwe, K.A., Duru, C.B., Diwe, K.C., Chineke, H.N., Merenu, I.A., Oluoha, U.R., Madubueze, U.C., Ndukwu, E. and Ohale, I. (2017) Knowledge, Attitude and Practices of Food Hygiene among Food Vendors in Owerri, Imo State, Nigeria. Occupational Diseases and Environmental Medicine, 5, 11-25. https://doi.org/10.4236/odem.2017.51002

Received: December 21, 2016

Accepted: January 21, 2017

Published: January 24, 2017

Copyright $\odot 2017$ by authors and Scientific Research Publishing Inc. This work is licensed under the Creative Commons Attribution International License (CC BY 4.0).

http://creativecommons.org/licenses/by/4.0/

\begin{abstract}
Background: Food vendors play a critical food safety role in the "farm to plate" continuum that is necessary for the prevention and control of food borne diseases and therefore, any lack of its understanding by the food vendors poses a serious challenge to food safety. Objective: To assess the knowledge, attitude and hygienic practices of food vendors in Owerri town of Imo State, Nigeria. Methods: The study was a Cross-Sectional descriptive design that used a proportionate convenience sampling technique to select 200 food vendors from the three Local Government Areas (LGAs) in Owerri town. Data were collected using a pretested semi-structured interviewer administered questionnaire. Descriptive analyses were done with frequencies and summary statistics. Chi square statistics were computed to determine significant relationships and $\mathrm{p}$ value was set at 0.05 significant level. Results: While a majority of the respondents had a good level of knowledge $(81 \%)$ and positive attitude $(71 \%)$ about food hygiene, only $37 \%$ of the respondents had a good level of hygienic practice. It was revealed that $32 \%$ and $46 \%$ of the respondents received training on food hygiene and environmental health worker inspection respectively. It was also revealed that, there were statistically significant relationships between knowledge $(p=0.001)$, attitude $(p=0.000)$, formal training on food hygiene $(\mathrm{p}=0.000)$ and the level of food hygienic practices. Conclusion: The public health management of food vending services should involve the development of strategies that will equip them with the necessary knowledge and skills to provide vending services in a hygienic and safe manner.
\end{abstract}




\section{Keywords}

Knowledge, Attitude, Practice, Food Hygiene, Food Vendors, Owerri, Nigeria

\section{Introduction}

The World health theme for 2015 was "Food Safety" and the slogan was "Farm to Plate, make Food Safe" [1]. This highlights the importance that the World Health Organization places on the need to globally address in a coordinated manner, the potential threats posed by unsafe food which is a consequence of the breakdown of food hygiene with the subsequent risk of the emergence of food borne illnesses along the pathway of the entire food supply chain, of which the food vendor is a critical component.

Food borne diseases are an important cause of morbidity and mortality worldwide with significant public health impact. The global burden of food borne diseases in 2010 was 33 million Healthy life years lost (DALY) with about 600 million food borne illnesses and 420,000 deaths, of which food borne diarrhoeal diseases, the most frequent cause of food borne illnesses contributed about 230,000 deaths [2] [3]. The burden of foodborne diseases is borne by individuals of all ages, particularly children under the age of 5 years who constitute about $40 \%$ of the global burden and also by individuals living in low-income regions. With considerable regional differences in the global burden of food borne diseases, Africa stands out, as having the highest burden per population of food borne diseases [2] [3].

In Sub-Saharan Africa especially Nigeria, despite the efforts of Government through its National Agency for Food and Drug Administration and Control (NAFDAC), to improve the safety of food supply, food safety still remains a major issue that has been exacerbated by the peoples' ignorance of food hygiene, Government's uncoordinated approach to food safety control and the poor enforcement of food safety legislation and regulations [4]. In addition, climate change resulting in temperature changes has been predicted to influence the risks associated with food production, storage and distribution and therefore has placed greater responsibility on food vendors to ensure the safety of food that they prepare for public consumption [3].

Unsafe food creates a vicious cycle of disease, diarrhoea and malnutrition which significantly impedes public health and socioeconomic development. The number of people buying and consuming food prepared in public places has increased as a result of population migration, changes in consumer demand and behaviour with urban dwellers needing cheaper foods in the face of harsh economic realities and as a consequence, the risk of food borne illnesses is more prevalent due to challenges in food safety especially in regions where adequate resources have not been allocated for food safety control and intervention efforts [3]. 
Food can become contaminated at any point of production and distribution along the farm to plate continuum and as a result, food safety control is a responsibility shared by all components in the food supply chain; so with each component operating responsibly, the supply of safe food to the consumer is supposed to be guaranteed. But unfortunately, a large proportion of food borne diseases are caused by improperly prepared and mishandled food by food vendors and also food handlers at home. The challenge in food safety is that these food handlers lack understanding of their roles in ensuring proper personal and environmental hygiene accompanied with the basic food hygienic practices when they buy, prepare and sell food [3].

The role of the food handlers especially the food vendors in effectively reducing the risk of food borne diseases is critically important as they are in direct contact with the consumers and also, they are the least challenging in terms of implementing food safety control measures. So assessing the knowledge, attitude and practices of food vendors will enable the development of coordinated, effective, integrated and preventive strategies in line with the WHO "Five Keys to Safer Food" with the aim of reducing the risk of contamination as they buy, prepare, store and serve food to the consumers [5].

\section{Methodology}

\subsection{Study Area}

The survey was conducted in Owerri town of Imo State, Nigeria. Owerri town is bordered to the east by Otamiri River and to the south by Nworie River and it comprises of three Local Government Areas; Owerri Municipal, Owerri North and Owerri West which are part of the 27 Local Governments that make up Imo State. Imo State is in the South Eastern part of Nigeria, within longitude $5^{\circ} 29^{\prime} 06^{\prime \prime} \mathrm{N}$ and latitude $7^{\circ} 02^{\prime} 06^{\prime \prime} \mathrm{E}$ occupying an area between the lower river Niger and the upper and middle Imo River [6]. It had a total population of 3.93 million (2.03 million males and 1.9 million females) by 2006 census with an expected population in 2013 of 4.95 million based on an annual growth rate of 3.2\% between 2006 and 2013 [7]. The State occupies an area of 5289.49 square kilometres with a population density of about 707.9 per square kilometre [6].

\subsection{Study Population}

The study population comprise of food vendors i.e. major hotels, school and hospital cafeterias, fast food restaurants, food kiosks, roadside food sellers and food hawkers.

\subsection{Sample Size Estimation}

The minimum sample size required was estimated using Cochran formula [8].

$$
n=Z^{2} p q / d^{2}
$$

when $n=$ minimum sample size required; $Z=$ Standard normal deviate corresponding to the probability of type I error; $p=$ proportion of food vendors esti- 
mated to have a certain knowledge, attitude and practice, which is set at $50 \% ; q$ $=1-p ; d=$ tolerable error of margin set at 0.05 . The minimum required sample size $(n)$ calculated was 384 . The population $(N)$ of the food vendors in Owerri was established to be 300 , using the finite population correction factor [9];

The adjusted sample size $\left(n_{0}\right)=n \times N / n+(N-1)$.

The adjusted sample size $\left(n_{0}\right)$ for this study was 169 but the researchers increased the sample size to 200 participants to accommodate non-response.

\subsection{Study Design and Sampling Technique}

The study was a cross sectional descriptive design that used a proportionate convenience sampling technique to select 200 food vendors from the three Local Government Areas (LGAs). The established population $(N)$ of 300 food vendors were located in the three LGAs as follows; Owerri Municipal-156 (52\%), Owerri North-69 (23\%) and Owerri West-75 (25\%). These proportions were applied to the study sample size of 200 and the proportionate number of food vendors selected from each LGA were identified as follows; Owerri Municipal104, Owerri North-46 and Owerri West-50. Subsequently, the food vendors were enrolled as participants based on convenience, accessibility, proximity and consent until the proportionate numbers for the respective LGAs were attained.

\subsection{Inclusion/Exclusion Criteria}

For each food vendor, the principal individual directly involved in the preparation of food was selected and there was no exclusion criteria applied.

\subsection{Data Collection and Analysis}

Data was collected from two hundred pretested semi structured intervieweradministered questionnaires with an observational checklist. The questionnaire comprise of 4 sections; section one, Sociodemographic Characteristics, section two, Knowledge of food hygiene, section three, Attitude towards food hygiene and section four, Practice and Training on food hygiene. The observational checklist comprise of 2 sections; Personal hygiene and Environmental hygiene. Medical students were recruited for the distribution and collection of the questionnaires.

The level of knowledge of food hygiene was determined by scoring the questions that assessed knowledge. For a single response question, a correct answer was scored 5; a false answer was scored 0. For a multiple response question, each correct answer was scored 5 and up to a maximum of 4 correct answers, a subtotal score of 20 was allocated and for a false answer, 0 was allocated. The total maximum score for all the correct answers for assessing the level knowledge was 35. The level of attitude towards food hygiene was determined by scoring questions that connote an appropriate attitude. For an appropriate attitude, a score of 5 was allocated and for an inappropriate attitude a score of 0 was allocated. The total maximum score for all the appropriate attitudinal response for assessing the level of attitude was 25 . The level of practice of food hygiene was determined 
by scoring questions that assessed practice. For an appropriate practice a score of 5 was allocated and for an inappropriate practice, a score of 0 was allocated. The total maximum score for all the appropriate practices was 25 . The aggregate score for each respondent according to the level of knowledge, attitude and practice was translated to a percentage and assessed against a scale of $0 \%-49 \%$ for poor, $50 \%-69 \%$ for fair and $70 \%$ or more as good. Data was cleaned, validated manually and analysed using Software Package for Social Sciences (SPSSIBM) version 22. Descriptive statistics (frequency tables and summary indices) were generated. Chi Square was used to test association between categorical variables with the $p$ value set at 0.05 significant level.

\subsection{Ethical Considerations}

Ethical approval was obtained from the Ethics Committee of Imo State University Teaching Hospital Orlu and verbal consents were given by the respondents. All authors hereby declare that the study has therefore been performed in accordance with the ethical standards laid down in the 1964 Declaration of Helsinki.

\section{Results}

Two hundred questionnaires were distributed with one questionnaire per food vendor and all were completely and correctly filled with a response rate of $100 \%$.

\subsection{Sociodemographic Characteristics}

More than half of the respondents (59.5\%) were between the ages of 21 and 40 years old with the majority of them, female (71.5\%), having either a secondary or tertiary school education (74.5\%), providing an informal food vending service (78\%) and were operating within Owerri Municipal Local Government Area of Imo State (52\%) (Table 1).

Table 1. Sociodemographic characteristics.

\begin{tabular}{ccc}
\hline Variable & Category & Frequency (\%) $\mathbf{n}=\mathbf{2 0 0}$ \\
\hline \multirow{2}{*}{ Age (years) } & $10-20$ & $25(12.5)$ \\
& $21-30$ & $66(33.0)$ \\
Gender & $31-40$ & $53(26.5)$ \\
& $>40$ & $56(28.0)$ \\
Educational level & Female & $143(71.5)$ \\
& Male & $57(28.5)$ \\
& Tertiary & $60(30.0)$ \\
LGA Residence & Secondary & $89(44.5)$ \\
& Primary & $34(17.0)$ \\
& None & $17(8.5)$ \\
& Owerri North & $46(23.0)$ \\
& Owerri West & $50(25.0)$ \\
& Owerri Municipal & $104(52.0)$ \\
& Formal & $44(22.0)$ \\
\hline
\end{tabular}




\subsection{Respondents Knowledge of Food Hygiene}

Most of the participants had heard of food hygiene (87\%) with more than one third of the respondents who were aware of food hygiene, indicating that their main sources of information were from television (38.5\%), health workers (36.2\%) and radio (35.1\%). More than half of the respondents (55.5\%) knew that diarrhoeal diseases were food borne and among those aware of food hygiene, majority (85.6\%) knew that lack of good food hygiene practice could cause disease (Table 2).

The aggregate score of the level of knowledge showed that $81 \%$ of the respondents had a good level of food hygiene knowledge (Figure 1).

Table 2. Knowledge of respondents on food hygiene.

\begin{tabular}{|c|c|c|}
\hline Variable & Category & Frequency (\%) \\
\hline \multirow{2}{*}{ Have you heard of Food Hygiene $(n=200)$} & Yes & $174(87.0)$ \\
\hline & No & $26(13.0)$ \\
\hline \multirow{4}{*}{${ }^{\star}$ Source of information about Food Hygiene $(n=174)$} & Television & $67(38.5)$ \\
\hline & Health workers & $63(36.2)$ \\
\hline & Radio & $61(35.1)$ \\
\hline & Others & $33(19.0)$ \\
\hline \multirow{3}{*}{ Lack of good food hygiene as a cause of disease $(n=174)$} & Yes & $149(85.6)$ \\
\hline & No & $7(4.0)$ \\
\hline & Don't know & $18(10.4)$ \\
\hline \multirow{5}{*}{${ }^{\star}$ Food borne diseases $(\mathrm{n}=200)$} & Diarrhoea & $111(55.5)$ \\
\hline & Typhoid & $76(38.0)$ \\
\hline & Malaria & $27(13.5)$ \\
\hline & Others & $6(3.0)$ \\
\hline & HIV & $1(0.5)$ \\
\hline \multirow{2}{*}{ Need for regular Medical check-up $(n=200)$} & Yes & $137(68.5)$ \\
\hline & No & $63(31.5)$ \\
\hline
\end{tabular}

${ }^{\star}$ Multiple response.



Figure 1. Levels of knowledge, attitude and practice of food hygiene. 


\subsection{Attitude of Respondents towards Food Hygiene}

Most of the participants (86.5\%) believed that food hygiene is important but only about half of the participants (52\%) were satisfied with their surrounding environmental conditions from where they provide food to the public. When buying food, a majority of the respondents (60.5\%) believed that freshness of the food being bought should be their most important consideration. Even though, most of the respondents believed in hand washing (93\%), a higher proportion, close to half of the respondents (46.5\%) believed that the water used in washing utensils should only be discarded when the water changes colour (Table 3).

A majority of the respondents (71\%) had a good level of positive attitude towards food hygiene (Figure 1).

\subsection{Practice of Food Hygiene and Services Provided to Respondents}

Majority of the respondents (70.5\%) use cold water and soap when washing their hands, after which they dry with a towel. While preparing and serving food, just more than half of the respondents (59\%) wear apron and cap and about half of the respondents (49.5\%) rinse the plate with water once after use. A majority of the respondents $(65.5 \%)$ did not go for an initial medical exam before commencing the food vending service and of those who went, only more than half of the respondents (59.4\%) went for periodic medical examination (Table 4).

Table 3. Attitude of respondents towards food hygiene.

\begin{tabular}{lcc}
\hline \multicolumn{1}{c}{ Variable } & Category & Frequency (\%) $\mathbf{n}=\mathbf{2 0 0}$ \\
\hline $\begin{array}{l}\text { Do you believe in the importance } \\
\text { of Food Hygiene }\end{array}$ & Yes & $173(86.5)$ \\
& Non't know & $1(0.5)$ \\
Are you satisfied with surrounding & Yes & $26(13.0)$ \\
environmental conditions & No & $104(52.0)$ \\
& Don't know & $78(39.0)$ \\
& Freshness & $18(9.0)$ \\
Most important belief when & Price & $121(60.5)$ \\
considering buying food & Quality & $38(19.0)$ \\
& Others & $36(18.0)$ \\
& Yes & $5(2.5)$ \\
Do you believe in hand washing & No & $186(93.0)$ \\
When do you believe that water, used in & Water colour change & $6(3.0)$ \\
washing utensils should be disposed & Water finishes & $83(4.0)$ \\
& Others & $77(38.5)$ \\
& Don't know & $28(14.0)$ \\
& After each use & $2(1.0)$ \\
\hline
\end{tabular}


Table 4. Food hygienic practices and services provided.

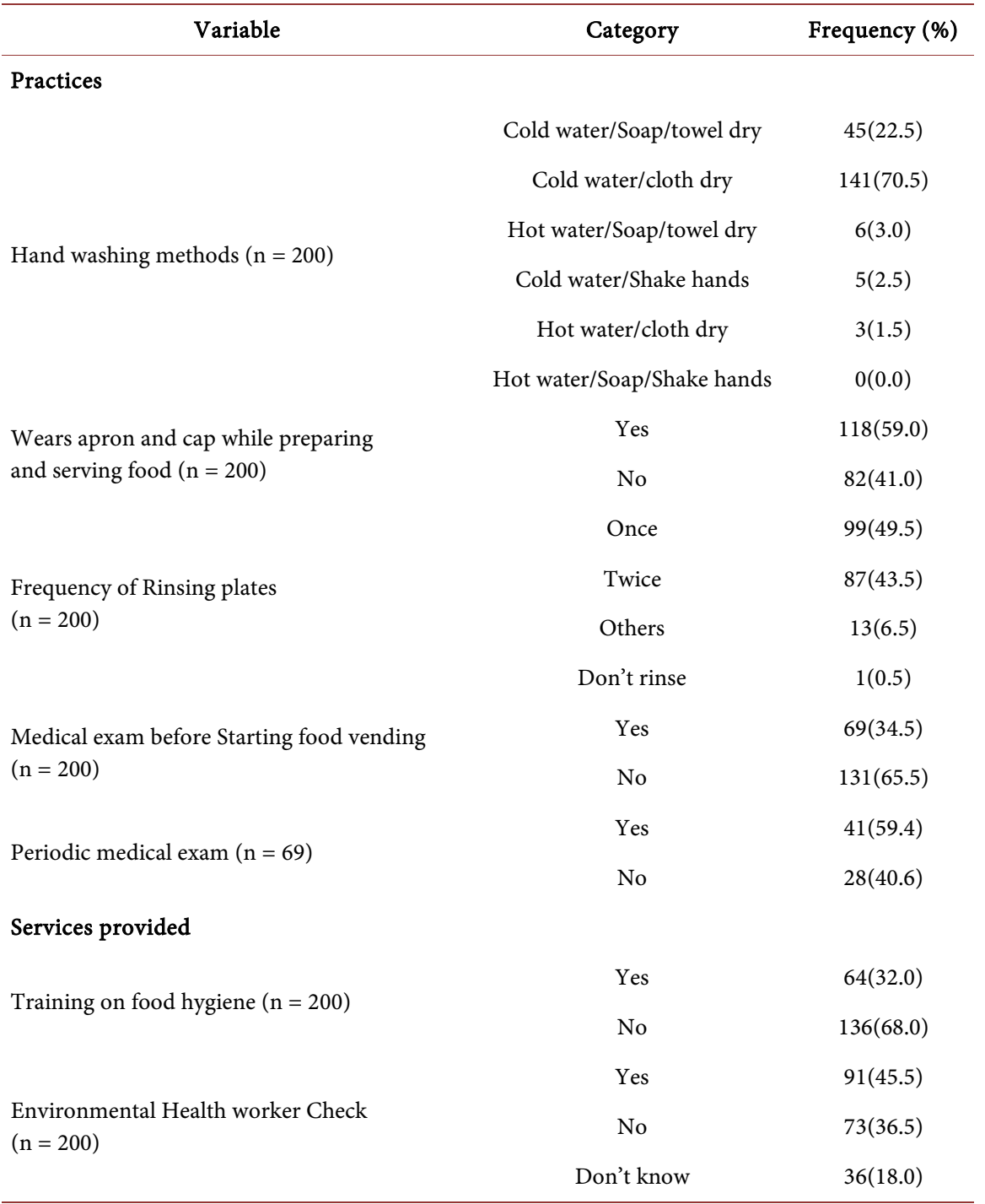

Furthermore, a majority of the respondents (68\%) did not undergo any training on food hygiene though about $46 \%$ of the respondents were visited at one time or the other by an environmental health worker (Table 4).

While only $36.5 \%$ of the respondents had a good level of food hygienic practice, $32 \%$ of respondents also had a poor level of food hygienic practice (Figure $1)$.

\subsection{Observational Check List of Personal/Environmental Hygiene of Respondents}

On inspection of personal hygiene of the respondents, a majority of them were neatly dressed (74\%) and did not use hair colouring (73\%) but only about half of the respondents had well-kept nails (52\%) or use an apron while preparing food (45\%). On further inspection of the surrounding environment, it was observed that a majority of the respondents protected both prepared (62.5\%) and stored (59.5\%) food from flies and rodents and did not place uncooked food on the 
floor unprotected (62.5\%). It was also observed that a majority of respondents had clean wash hand basin with soap and towel (60\%) with adequate supply of water $(63.5 \%)$ and at the same time maintaining a clean service table and surrounding (67\%) though, close to half of the respondents (49\%) had inadequate sanitary conditions with most of the respondents (85\%) having evidence of disease vectors in their premises (Table 5).

\subsection{Association of Knowledge, Attitude and Training with the Level of Food Hygienic Practices}

Knowledge of food hygiene $(\mathrm{p}=0.001)$, attitude towards food hygiene $(\mathrm{p}=$ $0.000)$ and training of respondents on food hygiene $(p=0.000)$ were significantly associated with the level of food hygienic practices (Table 6).

Table 5. Observational check list of personal/environmental hygiene.

\begin{tabular}{|c|c|c|}
\hline Variable & Category & Frequency $(\%) n=200$ \\
\hline \multicolumn{3}{|l|}{ Personal Hygiene } \\
\hline \multirow{2}{*}{ Neatly dressed } & Yes & $148(74.0)$ \\
\hline & No & $52(26.0)$ \\
\hline \multirow{2}{*}{ Well-kept finger nails } & Yes & $105(52.5)$ \\
\hline & No & 95(47.5) \\
\hline \multirow{2}{*}{ Use of hair colouring } & Yes & $54(27.0)$ \\
\hline & No & $146(73.0)$ \\
\hline \multirow{2}{*}{ Use of apron } & Yes & $90(45.0)$ \\
\hline & No & $110(55.0)$ \\
\hline \multicolumn{3}{|l|}{ Environmental Hygiene } \\
\hline \multirow{2}{*}{ Prepared food protected from flies and rodents } & Yes & $125(62.5)$ \\
\hline & No & $75(37.5)$ \\
\hline \multirow{2}{*}{ Stored food protected from flies and rodents } & Yes & $119(59.5)$ \\
\hline & No & $81(40.5)$ \\
\hline \multirow{2}{*}{ Presence of clean wash hand basin/soap/towel } & Yes & $120(60.0)$ \\
\hline & No & $80(40.0)$ \\
\hline \multirow{2}{*}{ Clean service table and surrounding } & Yes & $134(67.0)$ \\
\hline & No & $66(33.0)$ \\
\hline \multirow{2}{*}{ Evidence of disease vectors in premises } & Yes & $170(85.0)$ \\
\hline & No & $30(15.0)$ \\
\hline \multirow{2}{*}{ Uncooked food items placed on bare floor } & Yes & $75(37.5)$ \\
\hline & No & $125(62.5)$ \\
\hline \multirow{2}{*}{ Adequate supply of water } & Yes & $127(63.5)$ \\
\hline & No & $73(36.5)$ \\
\hline \multirow{2}{*}{ Adequate sanitary conditions } & Yes & $103(51.5)$ \\
\hline & No & $97(48.5)$ \\
\hline
\end{tabular}


Table 6. Association of Knowledge, Attitude and Training with the level of food hygienic practices.

\begin{tabular}{|c|c|c|c|c|c|c|c|}
\hline Variable & $\begin{array}{c}\text { Good-hygienic } \\
\text { Practice (\%) }\end{array}$ & $\begin{array}{c}\text { Fair-hygienic } \\
\text { Practice (\%) }\end{array}$ & $\begin{array}{c}\text { Poor-hygienic } \\
\text { Practice (\%) }\end{array}$ & Total (\%) & $x^{2}$ & $\mathrm{df}$ & $\mathrm{p}$-value \\
\hline Knowledge & & & & & 19.52 & 4 & $0.001^{*}$ \\
\hline Good & $69(42.6)$ & $50(30.9)$ & $43(26.5)$ & $162(100)$ & & & \\
\hline Fair & $3(17.6)$ & $7(41.2)$ & $7(41.2)$ & $17(100)$ & & & \\
\hline Poor & $1(4.8)$ & $6(28.6)$ & $14(66.7)$ & $21(100)$ & & & \\
\hline Total & $73(36.5)$ & $63(31.5)$ & $64(32.0)$ & $200(100)$ & & & \\
\hline Attitude & & & & & 49.00 & 4 & $0.000^{*}$ \\
\hline Good & $65(46.1)$ & $49(34.8)$ & $27(19.1)$ & $141(100)$ & & & \\
\hline Fair & $7(16.7)$ & $13(31.0)$ & $22(52.4)$ & $42(100)$ & & & \\
\hline Poor & $1(5.9)$ & $1(5.9)$ & $15(88.2)$ & $17(100)$ & & & \\
\hline Total & $73(36.5)$ & $63(31.5)$ & $64(32.0)$ & $200(100)$ & & & \\
\hline Training & & & & & 49.45 & 4 & $0.000^{*}$ \\
\hline Yes & $45(70.3)$ & $14(21.9)$ & $5(7.8)$ & $64(100)$ & & & \\
\hline No & $28(20.6)$ & $49(36.0)$ & $59(43.4)$ & $136(100)$ & & & \\
\hline Total & $73(36.5)$ & $63(31.5)$ & $64(32.0)$ & $200(100)$ & & & \\
\hline
\end{tabular}

*significant.

\section{Discussion}

This study assessed the knowledge, attitude and the level of practice of food hygiene among food vendors in Owerri town of Imo State, Nigeria; and overall, it revealed that knowledge, attitude and training were significantly associated with the level of food hygienic practice of food vendors.

In the present study, the respondents were mainly within the ages of $20-40$ years old, female with either a secondary or tertiary level of education and operating in Owerri municipal LGA which is an urban area. This trend is similarly observed in previous studies where the food vendors are predominantly female [10]-[17] within the ages of 20 - 40 years old [10] [13] [18] and have either a secondary or tertiary level of education [10] [11] [14] [17] [18]. On the contrary, some studies have observed that food vendors were predominantly male [19] [20] with no education or primary education as the highest level of education attained [12] [13] [16] [19].

With the difficult, harsh economic environment especially in developing countries, food vending business is rapidly expanding in the urban areas and serving as a common, accessible and complementing source of family income and employment especially for women, which is probably due to the existing cultural orientation and gender bias. The higher level of education observed among these food vendors may be attributed to the increasing lack of employment opportunities for the skilled and educated, thereby increasing the number of educated people engaging in self-employment activities like the food vending 
service as a source of livelihood.

It was observed that knowledge of the food vendors with regard to food hygiene was good for a majority of the respondents in the present study, and this observation was similar to some other studies done in Nigeria [14] [16] [21]. But on the contrary, studies from Ethiopia, Malaysia, Iran, Korea and Thailand observed that a majority of the food vendors had poor level of food hygiene knowledge [15] [18] [22] [23] [24] [25]. It is tempting to say that the level of good knowledge among the majority of food vendors in the present study could be related to the fact that a majority of the respondents had either a secondary or tertiary level of education which could have formed the basis for increased comprehension of food hygiene information and therefore improved knowledge. According to Kalua [26], knowledge, positively influences attitude formation and in other words, attitude can be said to be a reflection of knowledge which is linked to personal beliefs and previous personal experiences and this probably could explain the observation in the present study where a majority of the respondents had a good level of knowledge and also an accompanying good level of positive attitude towards food hygiene. This pattern was similarly observed in previous studies done in Nigeria [16] [21] where the majority of the respondents had a good level of both knowledge and attitude and in a study in Malaysia [18] where the majority of the respondents had a poor level of both knowledge and attitude.

According to Aiken et al. [27], practices refer to the ways in which people demonstrate their knowledge and attitude through their actions but in the present study, about one third of the respondents had a good level of food hygienic practice which appear not to be commensurate with the levels of knowledge and attitude observed in the majority of the respondents therefore appearing to have a disconnect between the levels of knowledge and attitude and the level of practice. The good level of hygienic practice observed in the present study in less than $50 \%$ of the respondents was also similarly observed in previous studies [16] [18] [25] with a range of only between $15 \%-32 \%$ of the respondents having a good level of food hygienic practice. This was not the case in a number of other studies, were more than $50 \%$ of the respondents had a good level of food hygienic practice [14] [15] [17] [24] [28]. Despite the low level of food hygienic practice observed in the present study, the practice of wearing aprons and covering the hair was observed in more than $50 \%$ of the respondents and this supposedly, should give an indication of the willingness of the food vendors to provide service in a hygienic manner. Though according to the World Health Organization (WHO), the use of aprons and hair covers by food vendors has more to do with aesthetics and consumer assurances than food safety [29].

On the other hand, a majority of the respondents did not do the required initial medical examination before commencing the food vending business and also of those that did, just more than half of the respondents subsequently went for periodic medical examinations. Probably the lack of awareness, additional costs or associated inconveniences, especially when they feel healthy, may have contributed to why the majority of the respondents did not do medical examina- 
tions. Though, Abdussalam et al. [30], is of the opinion that medical examination of food vendors prior to commencement or at periodic intervals thereafter, should not be mandatory, because it does not significantly ensure food safety. Notwithstanding, there is always a possibility of food vendors, being healthy carriers of disease and infecting consumers and as such, it is in the best interest of the consumer that all food vendors be examined.

On further analysis, it was revealed that the level of knowledge, attitude and formal training were significantly associated with food hygienic practices of the respondents. This was consistent with a number of studies; in Malaysia by Rahman et al. [18], where knowledge, attitude and training were significantly associated with practice, in Nigeria by Afolaranmi et al. [14], where knowledge and training were significantly associated with practice, in Ethiopia and Thailand by Tessema et al. [15] and Cuprasittrut et al. [25] respectively, where both studies reported that, knowledge was significantly associated with practice. On the contrary, a study in Nigeria by Otu S [21], reported that attitude was not significantly associated with practice and also a study in Ghana by Rheinländer et al. [31], reported that knowledge was not closely related to practice and this was attributed to the existing socio-cultural context which probably had a greater influence on safe food practices.

In the present study, formal training on food hygiene practices appear to be low with only $32 \%$ of the respondents having received training, and this appears to be a problem across developing countries as studies from Nigeria, Ethiopia, Malaysia and Thailand have reported a range of only between $12 \%-39 \%$ of food vendors having received training on food hygiene practices [13] [14] [24] [25] [28] [32] [33]. Formal training of food vendors is important in ensuring good personal and environmental hygiene and has been reported by Monney et al. [11] who showed that, food vendors trained on food hygiene and safety are more likely to keep their finger nails clean and adequately protect their food from flies and dust. Despite the low level of formal training in the present study, the observational check list on hygiene standard, showed that while close to three quarters of respondents were neatly dressed, only about half of the respondents had well- kept finger nails. Also while about $60 \%$ of respondents protected their food from flies and rodents, only about half had adequate sanitary conditions.

So in the present study, the level of personal and environmental hygiene appears to be fairly good, and therefore similar with some other studies [34] [35] whose authors have argued that, due to the food vendor's necessity to depend on the customer's repeat patronage in order to maintain and sustain their livelihood, the vendors are more likely inclined to produce relatively safe food by maintaining the minimum required level of hygiene standards; even though a serious gap still exists for the improvement of proper hygienic conditions and access to basic sanitary facilities for the food vendors.

\section{Conclusions}

With rapidly increasing number of food vendors especially in the urban areas 
and their access to a rapidly growing consumer base, there is a need for increased vigilance and control of the food vendor's practices through the enforcement of regulations, proper hygienic practices and food safety control measures by local authorities that are empowered to perform their functions without constraints, with the aim of preventing and controlling the potential risks and spread of disease.

In the interest of public health, the management of food vendors both mobile and stationary should involve the development of coordinated, effective, integrated and preventive strategies that emphasize vendor registration, formal training on hygienic practices, initial medical and periodic medical certification and regular personal and environmental hygiene checks.

\section{Acknowledgements}

We thank the food vendors that agreed to participate in the study and the research assistants in the data collection.

\section{Authors' Contributions}

All the authors participated in the study.

\section{Conflict of Interest}

The authors hereby declare that there is no conflict of interest.

\section{Source of Funding}

There was no external source of funding.

\section{References}

[1] World Health Organization (WHO) (2015) Health Days. http://www.who.int/campaigns/world-health-day/2015/en/

[2] World Health Organization (WHO) (2007-2015) Estimates of the Global Burden of Food Borne Diseases; Foodborne Disease Burden Epidemiology Reference Group. http://apps.who.int/iris/bitstream/10665/199350/1/9789241565165_eng.pdf?ua=1

[3] WHO Food Safety Fact Sheet No. 399. (2015) http://www.who.int/mediacentre/factsheets/fs399/en/

[4] Jane Omojokun (2013) Regulation and Enforcement of Legislation on Food Safety in Nigeria.

http://www.intechopen.com/books/mycotoxin-and-food-safety-in-developing-coun tries/regulation-and-enforcement-of-legislation-on-food-safety-in-nigeria

[5] World Health Organisation (WHO) (2006) Food Safety; Five Keys to Safer Food Program. http://www.who.int/foodsafety/areas_work/food-hygiene/5keys/en/

[6] Government of Imo State (2006) Statistical Year Book: Imo State Planning and Economic Development Commission, Owerri.

[7] Federal Republic of Nigeria (2009) National Population Commission Official Gazette. National Population Commission, Abuja.

[8] Cochran, W.G. (1963) Sampling Technique. 2nd Edition, John Wiley and Sons Inc., New York. 
[9] Roger Bove (2006) Estimation and Sample Size Determination for Finite Populations. 10th Edition, CD Rom Topics, Section 8.7, West Chester University of Pennsylvania.

http://courses.wcupa.edu/rbove/Berenson/10th\%20ed\%20CD-ROM\%20topics/secti on8_7.pdf

[10] Chukuezi, C.O. (2010) Food Safety and Hyienic Practices of Street Food Vendors in Owerri, Nigeria. Studies in Sociology of Science, 1, 50-57.

[11] Monney, I., Agyei, D. and Owusu, W. (2013) Hygienic Practices among Food Vendors in Educational Institutions in Ghana: The Case of Konongo. Foods, 2, 282-294. https://doi.org/10.3390/foods2030282

[12] Nurudeen, A.A., Lawal, A.O. and Ajayi, S.A. (2014) A Survey of Hygiene and Sanitary Practices of Street Food Vendors in the Central State of Northern Nigeria. Journal of Public Health and Epidemiology, 6, 174-181. https://doi.org/10.5897/JPHE2013.0607

[13] Musa, O.I. and Akande, T.M. (2003) Food Hygiene Practices of Food Vendors in Secondary Schools in Ilorin. Nigerian Postgraduate Medical Journal, 10, 192-196.

[14] Afolaranmi, T.O., Hassan, Z.I., Bello, D.A. and Misari, Z. (2015) Knowledge and Practice of Food Safety and Hygiene among Food Vendors in Primary Schools in Jos, Plateau State, North Central Nigeria. Journal of Medical Research, 4, 16-22.

[15] Tessema, A.G., Gelaye, K.A. and Chercos, D.H. (2014) Factors Affecting Food Handling Practices among Food Handlers of Dangila Town Food and Drink Establishments, North West Ethiopia. BMC Public Health, 14, 571.

https://doi.org/10.1186/1471-2458-14-571

[16] Bamidele, J.O., Adebimpe, W.O., Oladele, E.A. and Adeoye, O.A. (2015) Hygiene Practices among Workers in Local Eateries of Orolu Community in South Western Nigeria. Annals of Medical and Health Sciences Research, 5, 235-240. https://doi.org/10.4103/2141-9248.160176

[17] Okojie, P.W. and Isah, E.C. (2014) Sanitary Conditions of Food Vending Sites and Food Handling Practices of Street Food Vendors in Benin City, Nigeria: Implication for Food Hygiene and Safety. Journal of Environmental and Public Health, 2014, Article ID: 701316. https://doi.org/10.1155/2014/701316

[18] Rahman, M.M., Arif, M.T., Bakar, K. and Tambi, Z. (2012) Food Safety Knowledge, Attitude and Hygiene Practices among the Street Food Vendors in Northern Kuching City, Sarawak. Borneo Science, 31, 94-103.

[19] Muinde, O.K. and Kuria, E. (2005) Hygienic and Sanitary Practices of Vendors of Street Foods in Nairobi, Kenya. African Journal of Food Agriculture and Nutritional Development, 5, 1-15. http://www.ajfand.net/Volume5/No1/Muinde1060.pdf

[20] Duse, A.G., da Silva, M.P. and Zietsman, I. (2003) Coping with Hygiene in South Africa, a Water Scarce Country. International Journal of Environmental Health Research, 13, S95-S105. https://doi.org/10.1080/0960312031000102859

[21] Out, S.S. (2014) Food Hygiene Practices among Food Handlers in Ahmadu Bello University, Zaria. MPH Thesis Department of Community Medicine, Ahmadu Bello University, Zaria.

[22] Pirsaheb, M., Almasi, A. and Rezaee, M. (2010) The Special Education Course Effects on Knowledge, Attitude and Practice of Preparation, Distribution and Sale Centres Food Staff in Kermanshah. Iranian Journal of Health and Environment, 3, 299-308.

[23] Park, S., Kwak, T. and Chang, H. (2010) Evaluation of the Food Safety Training for Food Handlers in the Restaurant Operation. Nutrition Research and Practice, 4, 58 68. https://doi.org/10.4162/nrp.2010.4.1.58 
[24] Zain, M.M. and Naing, N.N. (2002) Sociodemographic Characteristics of Food Handlers and Their Knowledge, Attitude and Practice towards Food Sanitation: A Preliminary Report. Southeast Asian Journal of Tropical Medicine and Public Health, 33, 410-417.

[25] Cuprasittrut, T., Srisorrachatr, S. and Malai, D. (2011) Food Safety Knowledge, Attitude and Practice of Food Handlers and Microbiological and Chemical Food Quality Assessment of the Food for Making Merit for Monks in Ratchathewi Distict, Bangkok. Asia Journal of Public Health, 2, 27-34.

[26] Kalua, F. (2001) The Relationship between Knowledge, Attitude and Practices of Care Givers and Food Hygiene in Day Care Centers. MTech Degree Dissertation, Technikon Pretoria, Pretoria.

[27] Aiken, L.H., Clarke, S.P., Cheung, R.B., Sloane, D.M. and Silber, J.H. (2003) Educational Levels of Hospital Nurses and Surgical Patient Mortality. JAMA, 290, $1617-$ 1623. https://doi.org/10.1001/jama.290.12.1617

[28] Nigusse, D. and Kumie, A. (2012) Food Hygiene Practices and Prevalence of Intestinal Parasites among Food Handlers Working in Mekelle University Student's Cafeteria, Mekelle. Global Advanced Research Journal of Social Science, 1, 65-71.

[29] World Health Organization (1996) Essential Safety Requirements for Street-Vended Foods. World Health Organization, Geneva. http://apps.who.int/iris/handle/10665/63265

[30] Abdussalam, M. and Kaferstein, F.K. (1993) Safety of Street Foods. World Health Forum, 14, 191-194.

[31] Rheinländer, T., Olsen, M., Bakang, J.A., Takyi, H., et al. (2008) Keeping up Appearances: Perceptions of Street Food Safety in Urban Kumasi, Ghana. Journal of Urban Health, 85, 952-964. https://doi.org/10.1007/s11524-008-9318-3

[32] Omemu, A.M. and Aderoju, S.T. (2008) Food Safety Knowledge and Practices of Street Food Vendors in the City of Abeokuta, Nigeria. Food Control, 19, 396-402. https://doi.org/10.1016/j.foodcont.2007.04.021

[33] Kibret, M. and Abere, B. (2012) The Sanitary Conditions of Food Service Establishments and Food Safety and Knowledge and Practices of Food Handlers in Bahir Dar Town. Ethiopian Journal of Health Sciences, 22, 27-35.

[34] Martins, J.H. (2006) Socio-Economic and Hygiene Features of Street Food Vending in Gauteng. South African Journal of Clinical Nutrition, 19, 18-25. https://doi.org/10.1080/16070658.2006.11734085

[35] Von, H.A. and Makhoane, F.M. (2006) Improving Street Food Vending in South Africa: Achievements and Lessons Learned. International Journal of Food Microbiology, 111, 89-92. https://doi.org/10.1016/j.ijfoodmicro.2006.06.012 
Submit or recommend next manuscript to SCIRP and we will provide best service for you:

Accepting pre-submission inquiries through Email, Facebook, LinkedIn, Twitter, etc. A wide selection of journals (inclusive of 9 subjects, more than 200 journals)

Providing 24-hour high-quality service

User-friendly online submission system

Fair and swift peer-review system

Efficient typesetting and proofreading procedure

Display of the result of downloads and visits, as well as the number of cited articles Maximum dissemination of your research work

Submit your manuscript at: http://papersubmission.scirp.org/

Or contact odem@scirp.org 